\title{
Fostering Recovery and Functional Engagement of Children With Traumatic Brain Injury through Technological Supports: A Mini Review
}

\author{
Viviana Perilli ${ }^{1}$, Fabrizio Stasolla*2, Dominga Laporta ${ }^{3}$, Stefania Maselli ${ }^{1}$ and Isabel Morelli ${ }^{1}$ \\ ${ }^{1}$ Villa Apelusion Medical Care Center, Bari, Italy \\ ${ }^{2}$ University "Giustino Fortunato" of Benevento, Italy \\ ${ }^{3}$ The Other Home Day Center, Bari, Italy
}

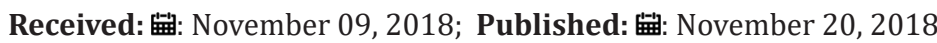

*Corresponding author: Fabrizio Stasolla, University “Giustino Fortunato” of Benevento, Italy

\begin{abstract}
We provide the reader with a mini review on the use of assistive technology-based interventions for recovering and fostering the functional engagement of children with traumatic brain injury. Traumatic brain injury, assistive technology, functional engagement, quality of life, recovery, and children were merged in Scopus database as keywords. The newest empirical evidences available were detailed and the clinical, educational, psychological, and rehabilitative implications of the findings were critically discussed. Some limitations and future research perspectives were additionally emphasized.
\end{abstract}

Keywords: Traumatic Brain Injury; Children; Assistive Technology; Quality of Life; Recovery; Engagement; Review

\section{Introduction}

Following a traumatic brain injury (TBI), children may experience significant communicative, intellectual, motor, and sensorial impairments with negative outcomes on their daily functioning, and deleterious consequences on their quality of life [1-3]. Additionally, they may encounter post-coma conditions, with a vegetative state, a minimally conscious state, or emerging from it [4-7]. Accordingly, they may be unable to positively interacting with the outside world. Enabling them with an adequate change of accessing to positive stimulation for promoting their independence and self-determination should be considered a crucial rehabilitative objective for parents and caregivers in daily settings [8-10]. However, enrichment programs may be at least only partially satisfactory. Thus, such interventions do not ensure the participant with an active role (i.e., independent) and do not guarantee that he/ she will receive the preferable amount of stimulation [11-12]. To overcome this issue, one may envisage assistive technology-based (AT) rehabilitative programs [13-15]. An AT-based intervention may be viewed as an affordable and valid alternative capable of assessing and monitoring the participant's independent responding and use it purposefully for getting access to the positive stimulation [16-18].
Undoubtedly, AT-based interventions will allow the child to (a) acquire an active role, pursue self-determination, and independently choose among different options, and (b) can be implemented at a relatively low cost with a minimal involvement of staff members, parents, and/or caregivers. In fact, the AT-based approach may be evaluated as a basic modification of direction if compared to the stimulation sessions. Specifically, within the enrichment/stimulation approach, the participant is considered as a passive recipient of the delivered stimulation. A wide amount of literature has been developed on the use of AT for adults, and a relevant number of review papers has been published on this specific topic [19-25]. Conversely, few empirical evidences exist on the use of AT-based programs for children with TBI and postcoma outcomes [26-27]. To fill this gap, we carried out the current mini-review including the newest evidence available on the use of AT-based interventions for recovering and fostering functional engagement of children with TBI. The objectives of the current review were

a) To provide the reader with an overview of the literature available within this framework, 
b) To emphasize strengths and weaknesses of te reviewed studies,

c) To critically discuss the outcomes, and

d) To suggest some useful future directions for both research and practice.

\section{Method}

A computerized search was performed in Scopus. Children, TBI, AT, quality of life, recovery, functional engagement, rehabilitation, post-coma, independence, and self-determination were merged as keywords. A manual search was additionally carried out as completion. Overall, twelve documents were found. The eligibility criteria concerned

a) At least an empirical contribution with an AT-based program,

b) At least a participant aged up to 19 years or less,

c) The English language for the published article, and

d) The last decade (i.e., 2008-2018) as publication range interval. Accordingly, four articles were critically reviewed. We detailed below a concise overview of the retained papers.

\section{Literature Review}

Stasolla et al. [28] exposed three children with TBI who were emerging from a minimally conscious state and aged between 9 and 12 years to an AT-based intervention aimed at promoting communication and leisure opportunities. First of all, though a computerized system an adapted software, the participants could communicate their needs among five basic categories (i.e., preferred songs, amusing videos, physical requests such as having cold, social contact with a parent, and pain) through small hand closures, which was recorded via a touch-sensitive double membrane microswitch. The microswitch was connected to the computer through an interface. Additionally, the participant could access to a literature program, with the opportunity to freely write their messages on a word processor. The intervention was conducted through a multiple-probe experimental design across behaviors and a onemonth post-intervention check for each participant. Additionally, indices of positive participants were recorded as an outcome measure of participants' constructive engagement.

Finally, forty-eight under-graduated students of Educational Sciences were recruited for a social validation assessment as external raters. Results showed an increased performance for all the participants involved, who improved their positive participation during the intervention phases compared to the baselines. The participants maintained their performance over the time. Social raters favorably scored the use of the AT-based program. Stasolla and De Pace [29] implemented an AT-based intervention for two adolescents who were aged of 12 and 14 years, and who suffered of a road accident two and three years prior to the beginning of the study, respectively. They experienced a coma condition of two and three weeks, respectively and underwent to a condition of vegetative state and minimally conscious state. Both emerged from it exhibiting the acquisition of consciousness and understandable responding, although they presented extensive motor impairments. The AT-based intervention was focused on request and choose preferred items among four categories, namely

a) Songs,

b) Videos,

c) Social Contact and

d) Personal Needs.

Sixty under-graduated students of Education Sciences were enrolled as external raters for a social validation procedure. The study was carried out according to a non-concurrent multiple baseline design across participants. Results emphasized an increased performance for both participants during intervention phases. The external raters favorably scored the use of the technology.

Vincent et al. [30] presented a case report of a client with a serious TBI, who four years after the accident was exposed to a brain computer interface, finalized at examining the computer performance (i.e., keyboard and mouse tasks), and the degree of realization of three functional activities (i.e., written communication, interpersonal relations, and leisure). The training lasted 16 weeks. A three-month follow-up was conducted. The activation of the computer was evaluated through lateral eye movements, relaxation waves, facial musculature, and brain activity waves. Results evinced no significant improvements of the computer performance after 8 weeks, while the trial of a different interface (i.e., tactile screen) made the optimization of mouse functions possible. A long and flexible computer training was successful for increasing the participant' performance. Unsal et al. [31] assessed a prospective study with 25 TBI children, who were rehabilitated in a pediatric rehabilitation unit. Age, sex, duration of disease, duration of rehabilitation recovery, etiological factors, and medical complications of the patients were recorded. Functional status of the children was monitored as ambulatory and non-ambulatory at admission and discharge. ST devices were additionally recorded. Results showed that children with TBI who received an early or late rehabilitation program, both benefited of the intervention. The number of ambulatory patients increased after both rehabilitation program and motor recovery.

\section{Discussion}

Data of the reviewed studies emphasized the successful use of AT-based interventions for promoting functional engagement of children with TBI and extensive motor impairments. The active role and self-determination of the participants involved were fostered and their constructive engagement increased. The indices of positive participation as outcome measure of the participants' quality of life significantly augmented. The performances were consolidated over the time. The external raters recruited for the social validation assessments formally endorsed the use of the AT-based programs. The findings were consistent with previous contributions [32-36] and suggested the following considerations. 
First, AT may be considered as affordable, effective, and suitable for enhancing the independence and self-determination of children with TBI and extensive motor disabilities. The participants could freely access to request and choice processes of preferred stimuli, literacy process, functional tasks, and/or occupation activities once equipped with the AT devices. Accordingly, the caregivers burden was relevantly reduced [37-38].

Second, the participants' positive participation as outcome measure of the quality of life and constructive engagement was improved. One may argue that the participants isolation and passivity were prevented, with positive consequences on their social image, desirability, and status. Consequently, the participants were capable of freely access to the positive stimulation by selecting and choosing the time and the amount of the stimulation [39-40]. Third, their performances were confirmed over the time. One may claim for the consolidation of the learning process. Thus, even if the intervention was suspended, the participants were able of favorably maintaining their performance, with beneficial effects on their functional opportunities [41-42]. Fourth, the external raters involved in the social validation procedures positively scored the use of the technology. In other words, the AT-based interventions were considered socially valid. One may argue that the clinical validity was empirically demonstrated [43-45].

\section{Limitations and Future Research}

Despite the aforementioned positive outcomes, our mini-review outlined some limitations. First, it was based only on the review of four studies. Further enlargement of the reviewed contributions were warranted. Second, the retained empirical contributions were based on single-subject experimental designs. Caution was mandatory for their generalization. Third, only 31 participants were considered. Accordingly, additional investigations were recommended. In light of the above, new research perspectives should deal with the following topics

a) Further empirical evidences involving new participants with TBI and extensive motor and/or communication delays,

b) New technological options finalized at responding to more sophisticated personal needs as consequence of their disabilities,

\section{c) Generalization phases and}

d) New social validation assessments, which should involve new external raters (e.g., psychologists, neurologists, physical, and/or speech therapists, parents of children with TBI).

\section{References}

1. Evald L (2018) Prospective memory rehabilitation using smartphones in patients with TBI. Disabil Rehabil 40: 2250-2259.

2. Baldassin V, Shimizu HE, Fachin-Martins E (2018) Computer assistive technology and associations with quality of life for individuals with spinal cord injury: A systematic review. Qual Life Res 27: 597-607.

3. Melo MC, Mac Edo DR, Soares AB, Krishnan S (2017) Technological aspects of traumatic spinal cord injury rehabilitation. In: IHTC 2017 IEEE Canada International Humanitarian Technology Conference p. 1115.
4. Lancioni GE, Belardinelli MO, Chiapparino C, Angelillo MT, Stasolla F, et al. (2008) Learning in post-coma persons with profound multiple disabilities: Two case evaluations. J Dev Phys Disabil 20: 209-216.

5. Lancioni GE, Belardinelli MO, Stasolla F, Singh NN, O'Reilly MF, et al. (2008) Promoting engagement, requests and choice by a man with post-coma pervasive motor impairment and minimally conscious state through a technology-based program. J Dev Phys Disabil 20: 379-388.

6. Formisano R, Aloisi M, Iosa M, Contrada M, Rizza F, et al. (2018) On the behalf of the Italian National Consortium on Functioning and Disability in Disorders of Consciousness Patients. A new tool to assess responsiveness in disorders of consciousness (DoC): A preliminary study on the brief post-coma scale (BPCS). Neurol Sci 39: 1651-1656.

7. Sullivan EG, Guernon A, Blabas B, Herrold AA, Pape TL, et al. (2018) Familiar auditory sensory training in chronic traumatic brain injury: A case study. Disabil Rehabil 40: 945-951.

8. Lancioni GE, Singh NN, O'Reilly MF, Sigafoos J, D'Amico F, et al. (2015) Assistive technology to help persons in a minimally conscious state develop responding and stimulation control: Performance assessment and social rating. NeuroRehabilitation 37: 393-403.

9. Haller CS (2017) Twelve-month prospective cohort study of patients with severe traumatic brain injury and their relatives: Coping, satisfaction with life and neurological functioning. Brain Inj 31: 1903-1909.

10. Nelson LD, Ranson J, Ferguson AR, Giacino J, Okonkwo DO, et al. (2017) Validating multi-dimensional outcome assessment using the traumatic brain injury common data elements: An analysis of the TRACK-TBI pilot study sample. J Neurotrauma 34: 3158-3172.

11. Hicks AJ, Gould KR, Hopwood M, Kenardy J, Krivonos I, et al. (2017) Behaviours of concern following moderate to severe traumatic brain injury in individuals living in the community. Brain Inj 31: 1312-1319.

12. Soberg HL, Roe C, Brunborg C, Von Steinbüchel N, Andelic N (2017) The norwegian version of the QOLIBRI - A study of metric properties based on a 12 month follow-up of persons with traumatic brain injury. Health Qual Life Outcomes 15(1): 14.

13. Martin S, Armstrong E, Thomson E, Vargiu E, Solà M, et al. (2018) A qualitative study adopting a user-centered approach to design and validate a brain computer interface for cognitive rehabilitation for people with brain injury. Assistive Technol 30: 233-241.

14. Groussard P, Pigot H, Giroux S (2018) From conception to evaluation of mobile services for people with head injury: A participatory design perspective. Neuropsychol Rehabil 28: 667-688.

15. Wade SL, Narad ME, Shultz EL, Kurowski BG, Miley AE, et al. (2018) Technology-assisted rehabilitation interventions following pediatric brain injury. J Neurosurg Sci 62: 187-202.

16. Brunner M, Hemsley B, Togher L, Palmer S (2017) Technology and its role in rehabilitation for people with cognitive-communication disability following a traumatic brain injury (TBI). Brain Inj 31: 1028-1043.

17. Radomski MV, Anheluk M, Penny Bartzen M, Zola J (2016) Effectiveness of interventions to address cognitive impairments and improve occupational performance after traumatic brain injury: A systematic review. Am J Occup Ther 70(3).

18. Leopold A, Lourie A, Petras H, Elias E (2015) The use of assistive technology for cognition to support the performance of daily activities for individuals with cognitive disabilities due to traumatic brain injury: The current state of the research. Neuro Rehabilitation [Internet] 37(3): 359-378.

19. Lancioni GE, Singh NN, O'Reilly MF, Sigafoos J, Amenduni MT, et al. (2012) Microswitch technology and contingent stimulation to promote adaptive engagement in persons with minimally conscious state: A case evaluation. Cogn Process 13: 133-137.

20. Lancioni GE, Bosco A, Belardinelli MO, Singh NN, O’Reilly MF, et al. (2010) An overview of intervention options for promoting adaptive behavior of 
persons with acquired brain injury and minimally conscious state. Res Dev Disabil 31: 1121-1134.

21. Bosco A, Lancioni GE, Belardinelli MO, Singh NN, O’Reilly MF, et al. (2010) Vegetative state: Efforts to curb misdiagnosis. Cogn Process 11(1): 87-90.

22. Bosco A, Lancioni GE, Belardinelli MO, Singh NN, O’Reilly MF, et al. (2009) Learning as a possible sign of non-reflective consciousness in persons with a diagnosis of vegetative state and pervasive motor impairment. Cogn Process 10: 355-359.

23. Stasolla F, Perilli V, Boccasini A, Caffò AO, Damiani R, et al. (2017) Intervention options for assessing and recovering post-coma persons in a vegetative state In: Columbus AM. Advances in Psychology Research New York, USA pp. 179-199.

24. Lancioni GE, Singh NN, O’Reilly MF, Sigafoos J, Oliva D, et al. (2014) Postcoma persons with multiple disabilities use assistive technology for their leisure engagement and communication. NeuroRehabilitation 34: 749-758.

25. Lancioni GE, O’Reilly MF, Singh NN, Buonocunto F, Sacco V, et al (2009) Technology-based intervention options for post-coma persons with minimally conscious state and pervasive motor disabilities. Dev Neurorehabilitation 12: 24-31.

26. Wade SL, Narad ME, Shultz EL, Kurowski BG, Miley AE, et al. (2018) Technology-assisted rehabilitation interventions following pediatric brain injury. J Neurosurg Sci 62: 187-202.

27. Hart T, Buchhofer R, Vaccaro M (2004) Portable electronic devices as memory and organizational aids after traumatic brain injury: A consumer survey study. J Head Trauma Rehabil 19: 351-365.

28. Stasolla F, Caffò AO, Damiani R, Perilli V, Di Leone A, et al. (2015) Assistive technology-based programs to promote communication and leisure activities by three children emerged from a minimal conscious state. Cogn Process 16: 69-78.

29. Stasolla F, De Pace C (2014) Assistive technology to promote leisure and constructive engagement by two boys emerged from a minimal conscious state. Neuro Rehabilitation 35: 253-259.

30. Vincent C, Bisson J, Langlois E, Voyer M, Cantin J, et al. (2010) Use of a brain-computer interface by a client presenting a brain injury. Can J Occup Ther 77: 101-112.

31. Ünsal S, Dülgeroğlu D, Barlak A, Özel S (2008) Clinical-demographical characteristics and rehabilitation outcomes of children with traumatic brain injury. J Rheumatol Med Rehabil 19: 137-140.

32. Clasby B, Hughes N, Catroppa C, Morrison E (2018) Community-based interventions for adolescents following traumatic brain injury: A systematic review. Neuro Rehabilitation 42: 345-363.

33. Stam D, Fernandez J (2017) Robotic gait assistive technology as means to aggressive mobilization strategy in acute rehabilitation following severe diffuse axonal injury: A case study. Disabil Rehabil Assistive Technol 12: 543-549.

34. Hammel J, Magasi S, Heinemann A, Gray DB, Stark S, et al. (2015) Environmental barriers and supports to everyday participation: A qualitative insider perspective from people with disabilities. Arch Phys Med Rehabil 96: 578-588.

35. Hassett L, Simpson G, Cotter R, Whiting D, Hodgkinson A, et al. (2014) A prospective interrupted time series study of interventions to improve the quality, rating, framing and structure of goal-setting in communitybased brain injury rehabilitation. Clin Rehabil 29: 327-338.

36. Babbage DR (2014) Research priorities for the assessment and treatment of emotion recognition difficulties in brain injury rehabilitation. Crit Rev Phys Rehabil Med 26:87-97.

37. Stasolla F, Boccasini A, Perilli V, Caffò AO, Damiani R, et al. (2014) A selective overview of microswitch-based programs for promoting adaptive behaviors of children with developmental disabilities. Int J Ambient Comput Intell 6: 56-74.

38. Doser K, Norup A (2016) Caregiver burden in Danish family members of patients with severe brain injury: The chronic phase. Brain Inj 30: 334342 .

39. Stasolla F, Damiani R, Perilli V, D’Amico F, Caffò AO, et al. (2015) Computer and microswitch-based programs to improve academic activities by six children with cerebral palsy. Res Dev Disabil 46: 1-13.

40. Stasolla F, Damiani R, Perilli V, Di Leone A, Albano V, et al. (2014) Technological supports to promote choice opportunities by two children with fragile $\mathrm{X}$ syndrome and severe to profound developmental disabilities. Res Dev Disabil 35: 2993-3000.

41. Stasolla F, Caffò AO, Albano V, Damato C, Stella A, et al. (2013) Promoting functional activities by a child with Down syndrome through self management of instruction cues. Psicol Clin Sviluppo 17: 347-358.

42. Gentry T, Wallace J, Kvarfordt C, Lynch KB (2008) Personal digital assistants as cognitive aids for individuals with severe traumatic brain injury: A community-based trial. Brain Inj 22: 19-24.

43. Perilli V, Stasolla F, Caffò AO, Albano V, D’Amico F, et al. (Microswitchcluster technology for promoting occupation and reducing hand biting of six adolescents with fragile X syndrome: New evidence and social rating. J Dev Phys Disabil pp. 1-19.

44. Perilli V, Lancioni GE, Laporta D, Paparella A, Caffò AO, et al. (2013) A computer-aided telephone system to enable five persons with Alzheimer's disease to make phone calls independently. Res Dev Disabil 34: 1991-1997.

45. Perilli V, Lancioni GE, Hoogeveen F, Caffó A, Singh N, et al. (2013) Video prompting versus other instruction strategies for persons with Alzheimer's disease. Am J Alzheimer's Dis Other Dem 28: 393-402.

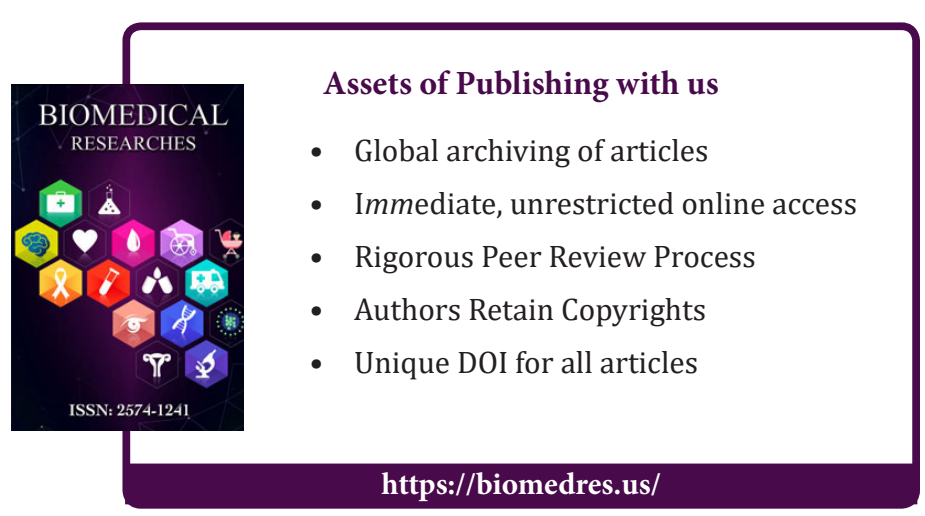

ISSN: 2574-1241

DOI: 10.26717/BJSTR.2018.11.002070

Fabrizio Stasolla. Biomed J Sci \& Tech Res

This work is licensed under Creative Commons Attribution 4.0 License

Submission Link: https://biomedres.us/submit-manuscript.php
Cite this article: Viviana Perilli, Fabrizio Stasolla, Dominga Laporta, Stefania Maselli, Isabel Morelli. Fostering Recovery and Functional Engagement of Children With Traumatic Brain Injury through Technological Supports: A Mini Review. Biomed J Sci \& Tech Res 11(2)-2018.BJSTR. MS.ID.002070. DOI: 10.26717/ BJSTR.2018.11.002070. 